\title{
A Fast On-Board Integrated Battery Charger for Four-Motor EVs
}

\author{
I. Subotic, M. Jones, E. Levi
}

\begin{abstract}
A novel type of fast on-board battery charger, applicable for four-motor electric vehicles (EVs), is presented in the paper. The charger consists exclusively of components that are already present on-board the vehicle. Having no new elements, it has a positive impact on the cost, weight and space saving in the vehicle. A three-phase grid is directly attached to the neutral points of three propulsion machines, so that hardware reconfiguration with respect to the propulsion mode of operation is not required. The charger operates with unity power factor and both charging and vehicle-to-grid (V2G) modes are feasible. The torque is not produced in the machines during the charging/V2G process. The charger is particularly suited for the interleaving process, which is used to improve the quality of the current that is taken/injected into the grid. A complete control algorithm for the charging/V2G operation is given, and performance of the charger, including torque-free operation feature, is validated by simulations.
\end{abstract}

Index Terms - Battery charger, electric vehicles, integrated on-board topology.

\section{INTRODUCTION}

$\mathrm{O}$ ne of the main concerns that people making a transition from internal combustion engine vehicle to EVs have is the ability to re-charge the vehicle's battery before it runs out of power. Today this demand is met by having a slow on-board charger in addition to fast off-board dc charging stations. The present standard in onboard chargers is that they are made and placed on board as separate units [1] ([1] also discusses some integrated chargers; however none of them has so far found a place in industry). This puts a limit on their size and weight, and consequently on their power, and this is the main reason why they are only capable of slow charging. However, if components that already exist on board the vehicle are utilized for charging purposes, improvements can be remarkable. Since there are fewer new elements in the vehicle, the cost and weight can be reduced, and spare space expanded. The idea of integration for the charging purposes is more than three decades old [2], and many proposals for integrated chargers have been reported since [3]-[6], mostly for single-phase charging.

As it is shown in [7] a great majority of EVs have either induction or permanent magnet synchronous propulsion motor. Nonetheless, at present only relatively small number of on-board integrated solutions [8]-[15] allow fast charging incorporating these types of machines.

A charging solution presented in [8] includes a machine in an open-end winding configuration. At one side the machine is connected to an inverter, while at the other is a

The authors would like to acknowledge the Engineering and Physical Sciences Research Council (EPSRC) for supporting the Vehicle Electrical Systems Integration (VESI) project (EP/I038543/1).

I. Subotic, E. Levi and M. Jones are with the Liverpool John Moores University, School of Engineering, Technology and Maritime Operations, Liverpool L3 3AF, U.K. (+44-151 231 2257; e.levi@ljmu.ac.uk). three-phase grid. As a rotating field gets developed during the charging process, the machine has to be mechanically locked in order to prevent its movement, which is a severe drawback. An isolated configuration is presented in [9]. It utilizes a three-phase machine with a wound rotor to act as a transformer during the charging process. Although it provides isolation, the overall cost of the drive is increased by having a wound rotor, and again a rotating field gets developed. Another isolated solution is presented in [10]. In order to minimize the cost it avoids a wound rotor and utilizes a stator with two sets of three-phase windings spatially shifted by 30 degrees (split-phase or asymmetrical six-phase configuration). In the propulsion mode the sets are connected in series to make a single three-phase winding set that can be connected to a three-phase inverter. For the charging mode a hardware reconfiguration is necessary. The set connected to the inverter keeps the same connections, and is connected into star on the other side. The second winding set is connected into delta and the terminals are connected to the three-phase grid. As with the previously described configurations, a rotating field is developed during the charging process.

Solutions [11]-[15] have a great advantage that there is no rotating field generation during the charging process. In [11] a three-phase machine supplied from a triple H-bridge inverter is integrated into the charging process. During the charging mode the three grid connections are connected directly to the mid-points of machine windings. However, in a standard three-phase machine there is no access to the mid-points of the machine windings, so that the machine has to be custom made (in essence a symmetrical six-phase machine). As the control operates to achieve the same currents through two half-windings of each machine's phase, they cancel each other's field. The configuration has a great advantage that it does not require any hardware reconfiguration between the propulsion and charging mode.

Another configuration that does not require any hardware reconfiguration is presented in [12]. It incorporates a nine-phase machine with three isolated neutral points into the charging process. In the charging mode the three-phase grid is attached to the three isolated neutral points of the machine. By ensuring that the same currents flow through all windings that are connected to the same grid phase it is achieved that they cancel each other's field within the set itself, so that there is no torque production in the machine.

The first fast integrated charger that found its place in industry is "Chameleon" charger - a solution from Renault [13]. At the power of $43 \mathrm{~kW}$ it is capable of charging the $80 \%$ of the battery capacity in thirty minutes. The vehicle's inverter and the synchronous motor with excitation winding are incorporated into the charging process. In addition to these components the charger has a junction box which is a 


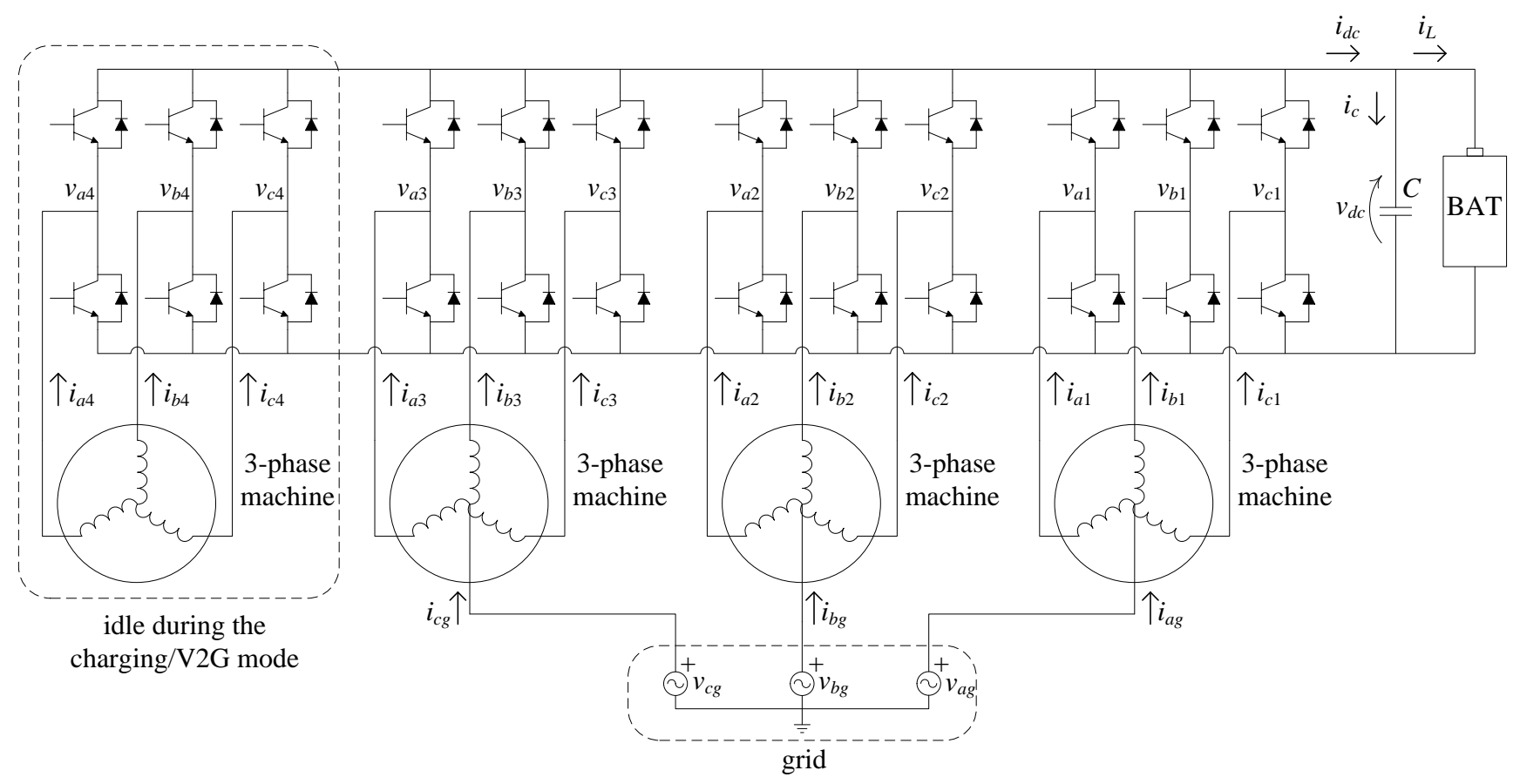

Fig. 1. Topology of the proposed fast integrated battery charging system.

non-integrated element. It is used to manage the charging process, to convert the alternating current into the direct current (thus requiring additional power electronics) and to communicate with the charging station. The torque is not developed during the charging process.

Solutions described in [14]-[15] consider charging from a multiphase source that is obtained from a three-phase grid. In the charging process a multiphase machine is put in an open-end winding configuration. At one side it is connected to an inverter, while the other side is connected to the multiphase voltage source. Both configurations employ the principle of phase transposition [16] to avoid torque production in the machine during the charging process. However, both of them require hardware reconfiguration between the operating modes.

This paper presents a novel fast integrated charger applicable to EVs with four propulsion motors. The type of the machine can be either a three-phase induction or a permanent magnet synchronous motor. During the charging process there is no rotating field or torque production in the machines. Charging process is completely integrated and it does not require any new components. Moreover, a hardware reconfiguration is not necessary between the charging and propulsion modes. The charging takes place with unity power factor and interleaving process is utilized to achieve high grid current quality.

The paper is organised as follows. The charging/V2G topology and the operating principle are presented in Section II. Section III provides the complete control algorithm for the proposed topology. Simulation results for both charging and V2G modes are given in Section VI. Section V concludes the paper.

\section{Operating Principles of The Charging/V2G SYSTEM}

Four-motor EVs, employing machines of induction or permanent magnet type, are particularly suitable for integration of the charging process. They were already

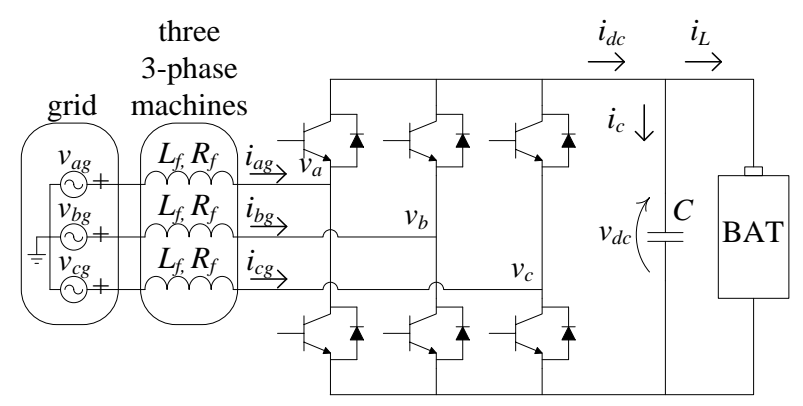

Fig. 2. The equivalent scheme for the charging/V2G mode.

considered in the past for these purposes [17], however the proposed configuration was capable only of slow (singlephase) charging.

This paper considers integration of a four-motor EV drive into a fast (three-phase) on-board charger. The charging is fast since it is no longer limited to $3.3 \mathrm{~kW}$ available with the single-phase mains. In principle, the charging limit is governed by the rated current of the machines (some derating will be required though, since the machines stay at standstill). The topology is shown in Fig. 1. In the propulsion mode the four motors are operated independently and are supplied from four three-phase inverters, with all dc buses of paralleled to the same battery.

In the charging mode three of the four propulsion motors are utilized. The three-phase grid connections are directly attached to three isolated neutral points of three motors, which must be accessible (similar to the phase winding mid-points in [11]). As these neutral points are already available, there is no need for any hardware reconfiguration in order to achieve charging. By simultaneous switching of all inverter legs belonging to the same inverter it is assured that the same currents flow through all the machine windings that are supplied from that inverter. These currents cancel each other's field so that there is no field in the rotor, and consequently no torque production. Machine windings act as simple resistance-inductance passive components. The $\alpha-\beta$ plane of the machine is left without 


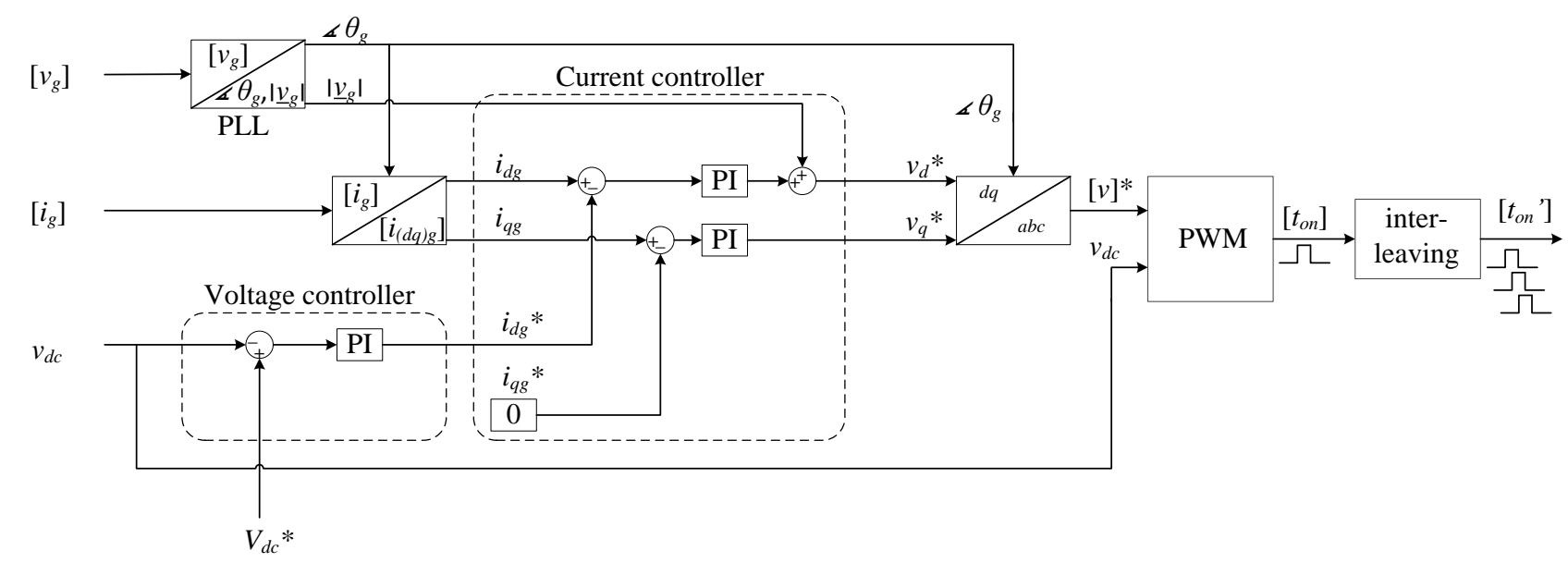

Fig. 3. Controller structure for the charging process.

excitation, and the charging process utilizes only the zerosequence currents, that are incapable of producing a torque. Machines' rotors stay at standstill during this process; thus they do not need to be mechanically locked.

The equivalent charging circuit of the configuration of Fig. 1 is presented in Fig. 2. Each machine is represented with a single inductance $L_{f}$ and resistance $R_{f}$. The inductance has the value of individual machine's zerosequence inductance - one third of the machine's stator leakage inductance, and the resistance is one third of the machine's stator resistance. As can be seen, the equivalent configuration represents a simple three-phase PFC (power factor correction) rectifier, and should be controlled accordingly. The advantage of the proposed configuration over the standard three-phase PFC converter is that once the gating signals are calculated the interleaving process can be applied in order to reduce grid current ripple. The complete control algorithm for the charging/V2G mode is given in the next section.

The difference between induction and PM machines is only in the rotor configuration. Since zero-sequence stator current in a machine cannot produce a rotating field, the rotor will not be excited, regardless of the machine's type. Therefore, the charging/V2G performance will be the same for both induction and PM machines and the rotor will stay at standstill regardless of the machine type. The performance is dependent only on the stator resistance and leakage inductance. Since there is only leakage flux in the machine, iron losses can be expected to be small (and there will be no rotor winding losses in induction machines).

\section{CONTROL AlgOrithm FOR THE CHARGING/V2G OPERATION}

Voltage oriented control (VOC) is chosen for the control of the proposed configuration during the charging/V2G process in order to ensure unity power factor operation. Its complete control scheme is presented in Fig. 3. As can be seen, it requires knowledge of grid voltages, grid currents and dc-bus voltage. However, compared to the sensors already required for the propulsion, only additional grid voltage sensors are needed. The information related to each grid current can be obtained by summing the three phase currents of each machine that are measured anyway.

In order to achieve unity power factor, the grid position has to be known. For this purpose, a phase-locked loop

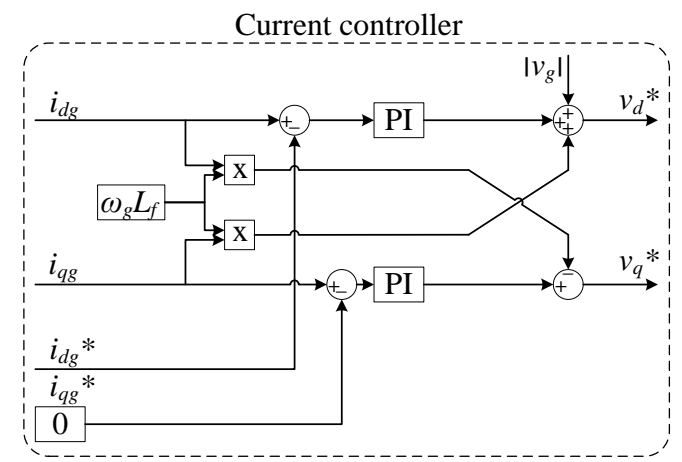

Fig. 4. Decoupling network.

(PLL) is commonly utilized. Once it is obtained, the information on the grid position is used to transform the grid currents into the reference frame that is grid voltage oriented. This transformation isolates the grid current component that is in phase with the grid voltage ( $d$ component) from the one that is shifted by 90 degrees ( $q$ component). In order to have unity power factor, only the component in phase with the voltage should remain, thus the charging/V2G process should employ only $d$ component. The $q$-component should be kept at zero during the whole process. As both $d$ - and $q$-component are dc quantities, they can be controlled to follow their references with PI controllers that can be seen in Fig. 3. The sign at the input of the controller $\left(i_{d g}-i_{d g}{ }^{*}\right)$ is in accordance with the fact that when the amplitude of converter voltages increases, voltage on the filter decreases, and vice versa.

It should be noted that current components are not independent. If one of them is changed it causes the change of the other one as well. This is why a decoupling network is necessary in order to achieve the independent control. For the clarity reasons this network is omitted from Fig. 3 and is shown separately on Fig. 4.

The most common way of charging the EVs battery is CC-CV (constant current - constant voltage) method. It consists of charging the battery at constant maximum current until the point when the voltage reaches certain cutoff level, from which the battery charged with the constant voltage [18]. The charging stops when the charging current drops to below $10 \%$ of its maximum value. If the charging is with unity power factor, the difference between the dcbus and battery voltage is directly proportional to the charging current. Thus the reference for the $d$-current component can be obtained from a dc-bus voltage 


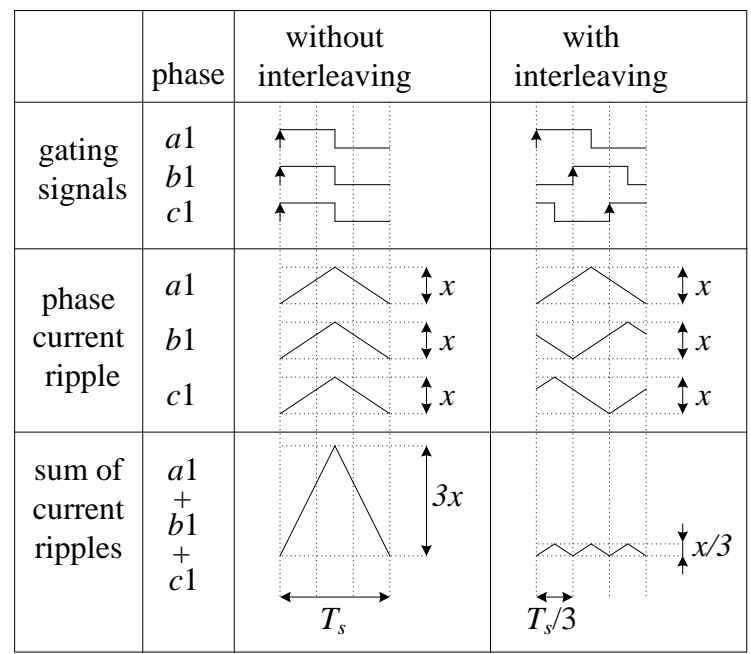

Fig. 5. Interleaving process for the modulation index $m=0.5$.

controller. This controller presents an outer control loop in Fig. 3, and is utilized in the CV mode. In the CC mode the reference for the $d$-component is a constant.

The V2G operation presents a new operating mode, however the same control diagram of Fig. 3 can be applied without any modification. The only difference with respect to the charging mode is that the reference for the $d$-current component should have an opposite sign.

Finally, the outputs of the current controllers, after the inverse rotational and decoupling transformation, go into a PWM block. A simple carrier-based PWM with a zerosequence injection is utilized as the modulation strategy. However the interleaving process is employed in order to minimize the grid current ripple, and to obtain nine out of three gaiting signals. This block is considered separately in what follows.

In the propulsion mode the drive is operated according to the field oriented control (FOC), which is a well-known control method; it is therefore not considered here.

\section{A. Interleaving process}

The interleaving process shifts the gating signals of phases that are connected to the same grid phase. For the case of a connection of three phases, as is the case here, their carriers are shifted by 0,120 , and 240 degrees. This shift allows certain cancellation of switching harmonics between phases, so that they do not enter the common branch (grid). The interleaving process was already proposed to be used in integrated chargers in [19]-[20], although only for single-phase charging. Here its application on three-phase charging/V2G process is proposed.

The operating principle of the interleaving process for the proposed configuration is given in Fig. 5. Gating signals for the observed phases before the interleaving are identical. Two modes are considered and compared in Fig. 5: one with interleaving (right part of the Fig. 5) and one without it (the left part). The modulation signal is taken to have a value of $m=0.5$. As can be seen from the left part, the gating signals are in phase, thus the currents that flow through three phases are identical. The grid phase current is a simple sum of these currents and it has identical shape as each one of them. However, the grid current has three times higher absolute ripple than the phases that are connected to it. On the other hand, if the interleaving process is applied (the right part of Fig. 5), the gating signals are mutually shifted by 120 degrees, and consequently, although the currents that flow through phases are very similar, they have ripple peaks at different locations. The sum of these currents is the grid current, but now it has only the amplitude that is three times higher than the one of individual phases. As can be seen its ripple is substantially reduced (nine times for the particular case of $m=0.5$ ). It should be noted that this reduced ripple has a frequency three times higher than the switching frequency.

Interleaving introduces some field in the machine that originates from differences in the ripple between phases. However, the impact of various rotor types on this ripple is not considered in this paper.

\section{Simulation Results of the Charging/V2G Process}

Simulations in Matlab/Simulink environment are performed in order to verify the unity power factor operation without torque production in the machines during the charging/V2G mode. The three-phase grid voltage is taken as purely sinusoidal, with per-phase rms of $240 \mathrm{~V}$, and $50 \mathrm{~Hz}$ frequency. The battery is represented with a series connection of an ideal voltage source and a resistance of $R_{L}=0.5 \Omega$. All converters have a common dc-bus capacitor $C_{d c}=1.5 \mathrm{mF}$, and they are operated at a switching frequency of $2 \mathrm{kHz}$ with a dead time of $6 \mu \mathrm{s}$. There-phase $50 \mathrm{~Hz}$ induction machines have the following per-phase parameters: $R_{s}=R_{r}=5 \Omega, L_{\gamma s}=L_{\gamma r}=60 \mathrm{mH}, L_{m}=500 \mathrm{mH}$ two pole pairs, $J=0.1 \mathrm{kgm}^{2}$. The parameters are of a real machine, which is however not optimized for vehicular applications. In simulations the leakage inductances are identical for all phases. However, in a real machine there might be some difference in parameters among phases; thus additional current controllers may be required to compensate possible asymmetries. Both charging and V2G operating modes are considered.

\section{A. Charging Mode}

For the charging mode of operation the ideal voltage of a battery is chosen to have a value of $E=595 \mathrm{~V}$. However, this value is not fixed as many EVs posses a dc-dc converter between the converter and the battery, which can ensure fixed dc-bus voltage regardless of the battery state-ofcharge. This allows additional freedom so that the equivalent ideal battery voltage can be adjusted in accordance to the mode of operation (if dc-dc converter exists on-board). As it will be seen, in the next subsection a different value is used for $E$. The reference value for the dcbus voltage is set to $600 \mathrm{~V}$.

Waveforms of grid phase voltage $v_{a g}$ and current $i_{a g}$ are presented in Fig. 6a. A unity power factor is obvious as the current and voltage are in phase. It can be seen that grid current has very low ripple due to the employment of the interleaving process, despite the fact that the equivalent phase inductance is equal to one third of the machine's leakage inductance. As can be seen from Fig. 6b the grid current has negligibly small low order harmonics. Switching harmonics are greatly reduced by the interleaving process and moved from the switching frequency $(2 \mathrm{kHz})$ to triple the switching frequency $(6 \mathrm{kHz})$, 


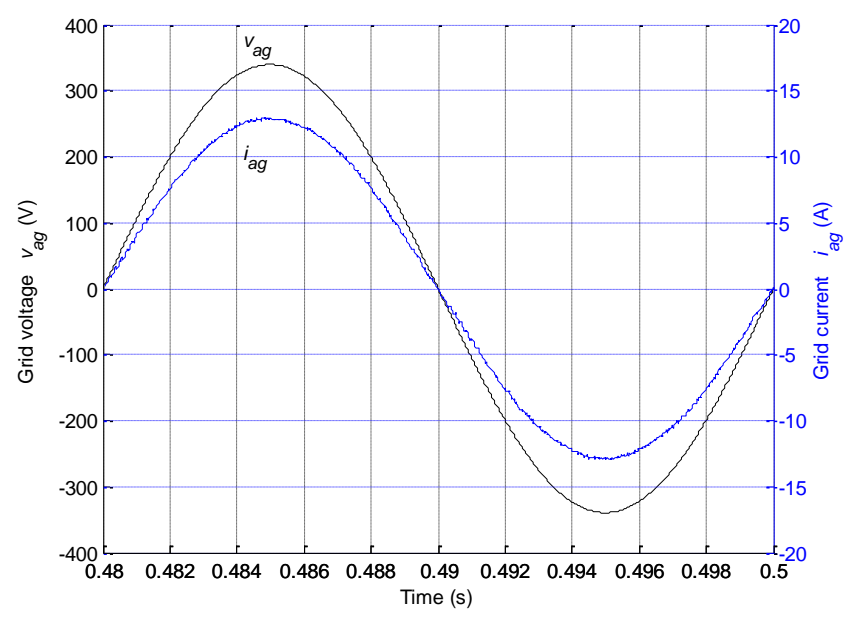

a)

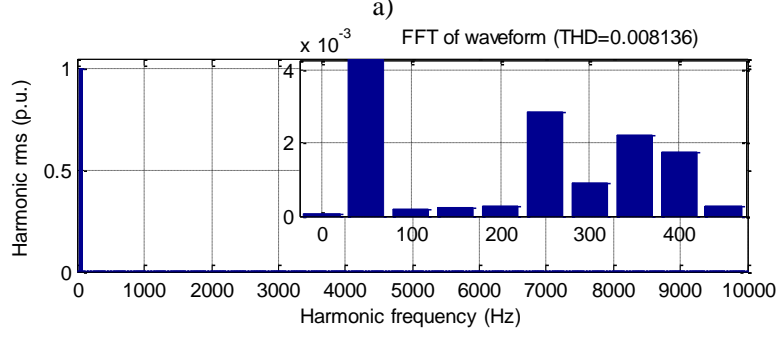

b)

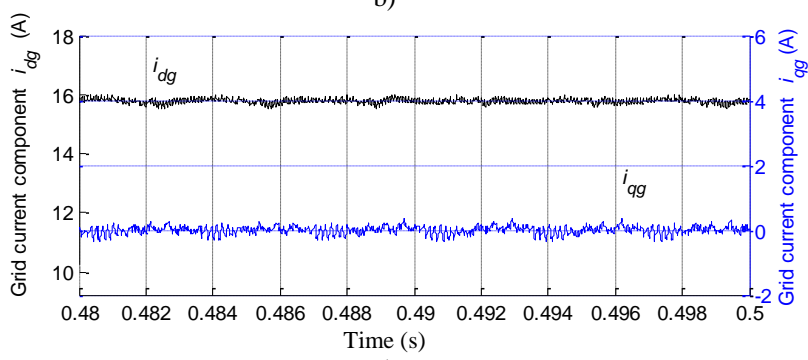

c)

Fig. 6. Charging mode: (a) Grid phase voltage and current, (b) grid current spectrum, (c) grid current components.

so that they are not obvious in Fig. 6b. Grid current components in the $d-q$ plane are shown in Fig. 6c. The $q$ component is kept at zero which, considering that the reference frame is grid voltage oriented, confirms the unity power factor. The $d$-component is controlled at a constant value which is governed by the dc-bus voltage controller.

In Fig. 7a the first machine's phase current $i_{a 1}$ and its spectrum are given. It can be seen that the current has much higher ripple than the grid current (Fig. 6a), which is due to the interleaving process. The third harmonic is noticeable and it is caused purely by the zero-sequence (third harmonic) injection. Although it is improving the dc-bus utilization, the third harmonic injection does not go entirely into the zero-sequence when the interleaving process is used. Since it is delayed by the interleaving, this harmonic is shifted between the interleaved phases (in this particular case $a 1, b 1$ and $c 1)$ by $(1 / 3) \cdot\left(1 / T_{s}\right)=0.167 \mathrm{~ms}$, which is one fortieth of the third harmonic period. This shift causes unequal harmonic injection among the three phases. The result is that only the injection into the second phase goes completely into zero-sequence, while a part of injections into the first and the third phase end up as the third harmonic that circulates through these two phases, and does not enter the grid. In order to avoid this harmonic a modified zero-sequence injection has to be implemented.
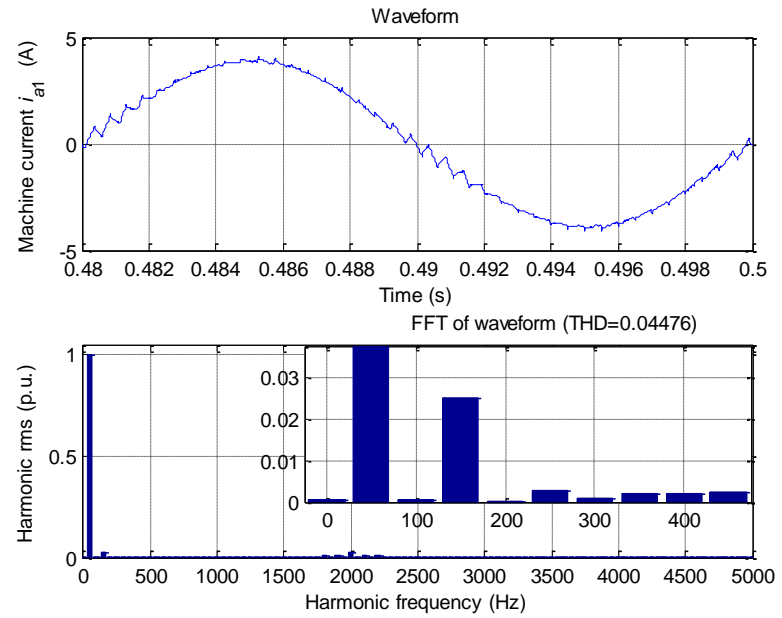

a)
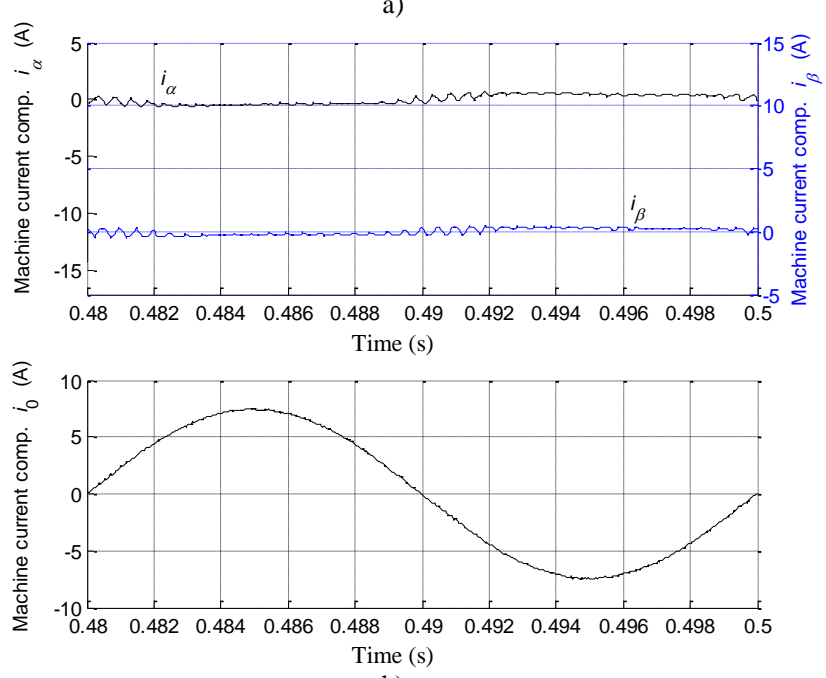

b)

Fig. 7. First machine's: (a) phase current and its spectrum (b) current components $i_{\alpha}, i_{\beta}$ and $i_{0}$.

However, this is beyond the scope of this paper.

Fig. $7 \mathrm{~b}$ illustrates the first machine's current components. The currents of the first $(\alpha-\beta)$ plane are kept close to zero, albeit with negligible oscillations that are due the interleaving process. As this plane is not excited there will be no torque production in the machine. It is obvious that the whole charging process takes place with the zerosequence component $i_{0}$, which has the same shape as the grid current (Fig. 6a). It can be seen that the most of the current ripple around switching frequency relates to the $(\alpha$ $\beta$ ) plane and is absent from the zero-sequence current.

Fig. 8a shows that the torque average value is zero, and that the first motor is at standstill during the whole charging process. Fig. $8 \mathrm{~b}$ illustrates that the dc-bus voltage is controlled at $600 \mathrm{~V}$ without a steady state error, and that the charging current is, as expected, of the same shape as the voltage.

\section{B. V2G Mode}

This subsection considers the proposed topology's capability of injecting the energy back into the grid. A bidirectional dc-dc converter is assumed between the battery and the converter. As noted, in this case the voltage value of the ideal voltage source is not fixed. A different value of $E=705 \mathrm{~V}$ is now considered.

In order to achieve $\mathrm{V} 2 \mathrm{G}$ operation the reference for the dc-bus voltage has to be lower than the battery voltage. 


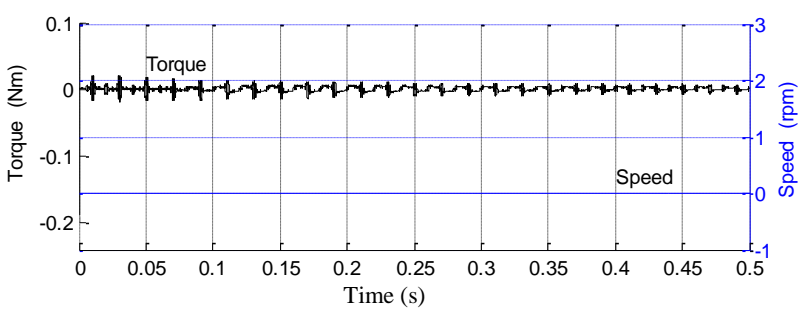

a)

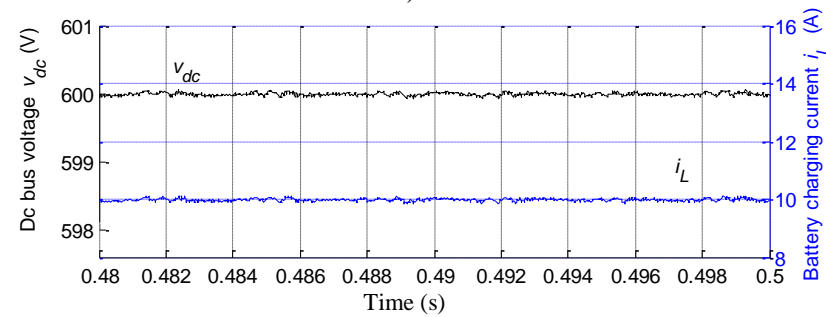

Fig. 8. (a) First machine's torque and speed, (b) dc-bus voltage and charging current.

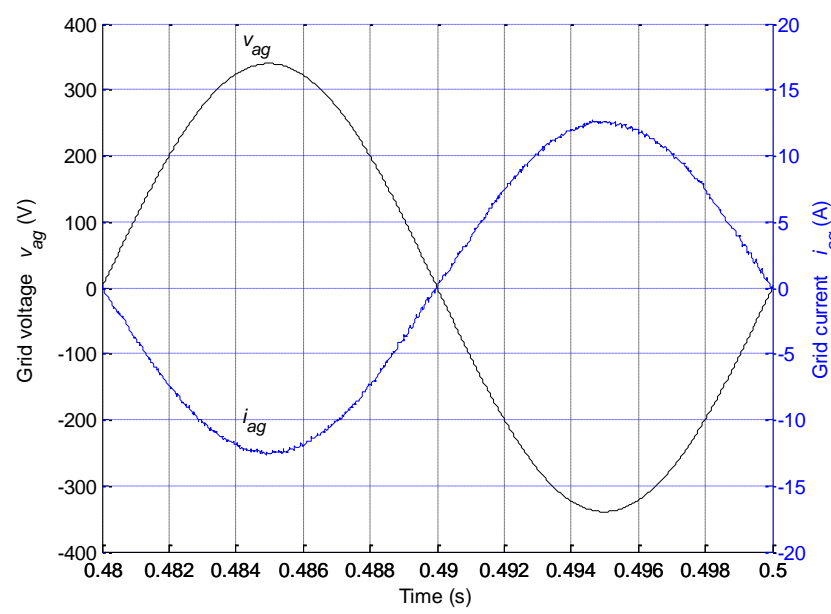

a)

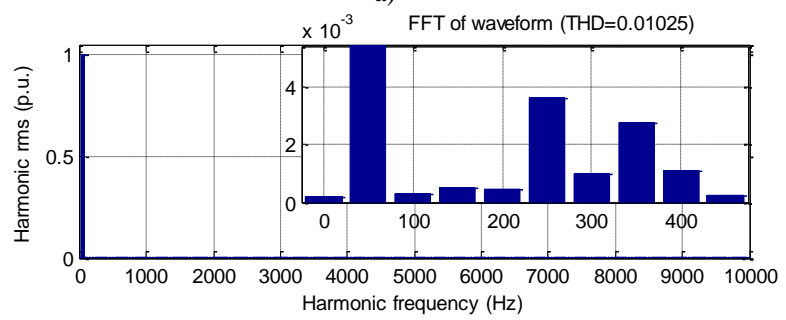

b)

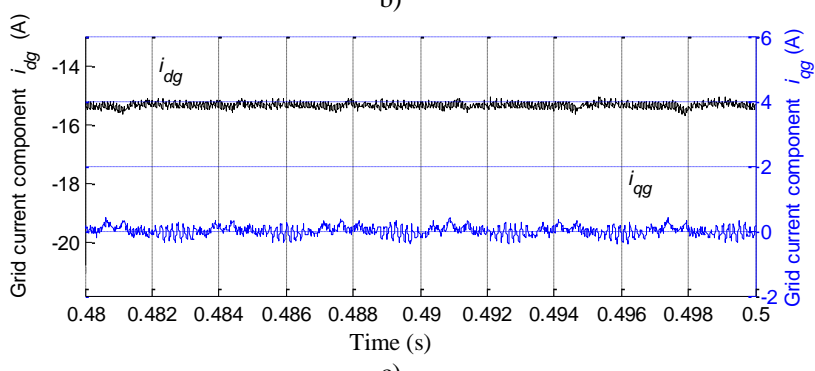

Fig. 9. V2G mode: (a) Grid phase voltage and current, (b) grid current spectrum, (c) grid current components.

It is set here to $700 \mathrm{~V}$. The higher dc-bus voltage is considered for this mode of operation since the converter has to produce a higher voltage fundamental, that has to be high enough to exceed the grid voltage fundamental by a voltage drop on the machine windings.

The grid phase voltage and current are presented in Fig. 9a. The voltage and current are in counter-phase, and it is obvious that the energy is returned into the grid at unity
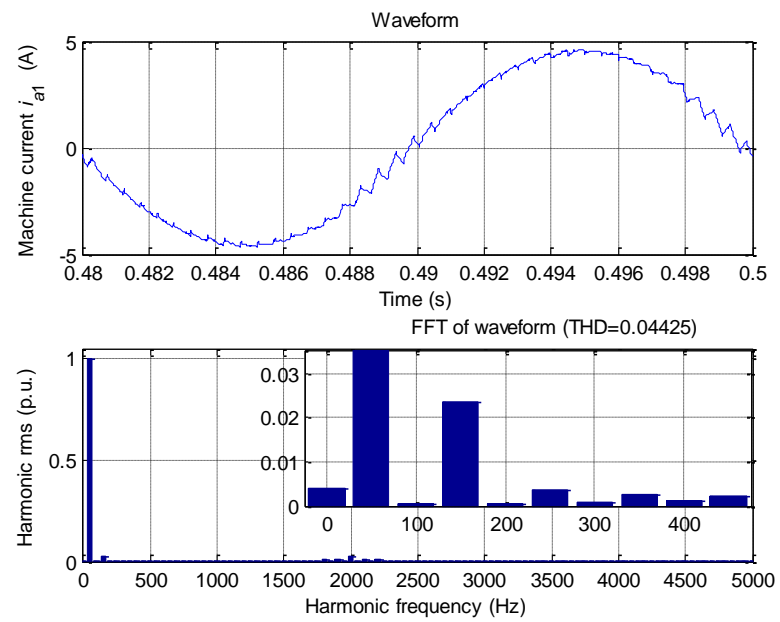

a)
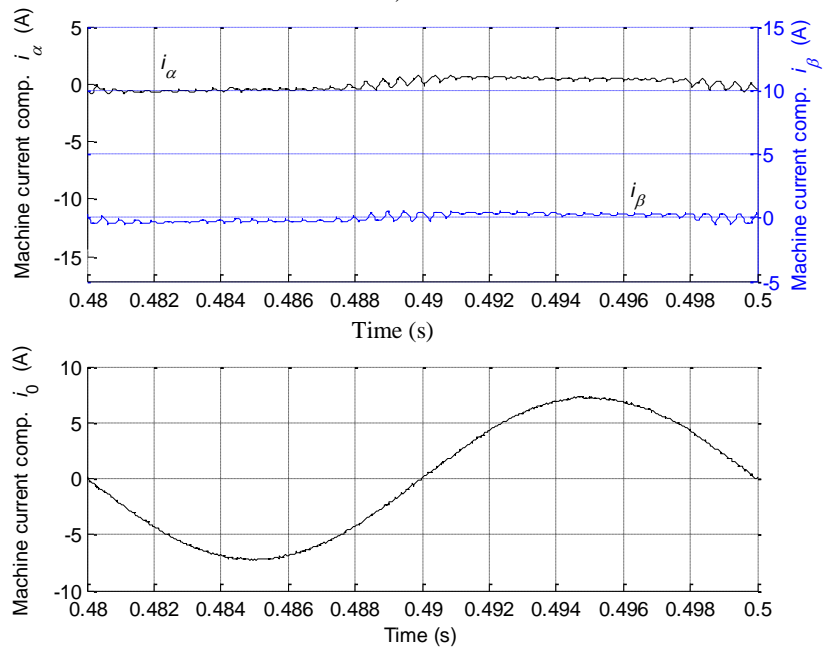

b)

Fig. 10. First machine's: (a) phase current and its spectrum (b) current components $i_{\alpha}, i_{\beta}$ and $i_{0}$.

power factor. Again the grid current has very low ripple. The grid current spectrum is depicted in Fig. 9b. As for the charging mode, it practically does not contain low order harmonics. Fig. 9c shows grid current components. The $q$ component is kept at zero while the $d$-component has a constant value. If compared to Fig. $6 \mathrm{c}$ it can be seen that the $d$-component has a negative sign, and lower absolute value than for the charging process. This is regardless of the fact that the same voltage difference (by absolute value) exists between the battery and the dc-bus. The amplitude difference is explained by the fact that in the charging mode the grid has to provide the power for the losses in the filter (machines) in addition to the battery charging power. On the other hand, for the V2G mode the power that is injected into the grid is what is left from the battery discharging power after the filter losses. Since the grid voltage is fixed, the $d$-axis current component naturally reduces. Thus the difference originates from the sign of the machine losses.

The first machine's phase current $i_{a 1}$ is presented in Fig. 10a. As for the charging mode it contains the third harmonic due to zero-sequence injection. Other low order harmonics are negligible. From Fig. 10b it can be seen that the $\alpha-\beta$ plane is left without excitation allowing the torquefree operation. The zero-sequence current component is in charge of the power transfer.

Finally, Fig. 11a shows that there is again no average 

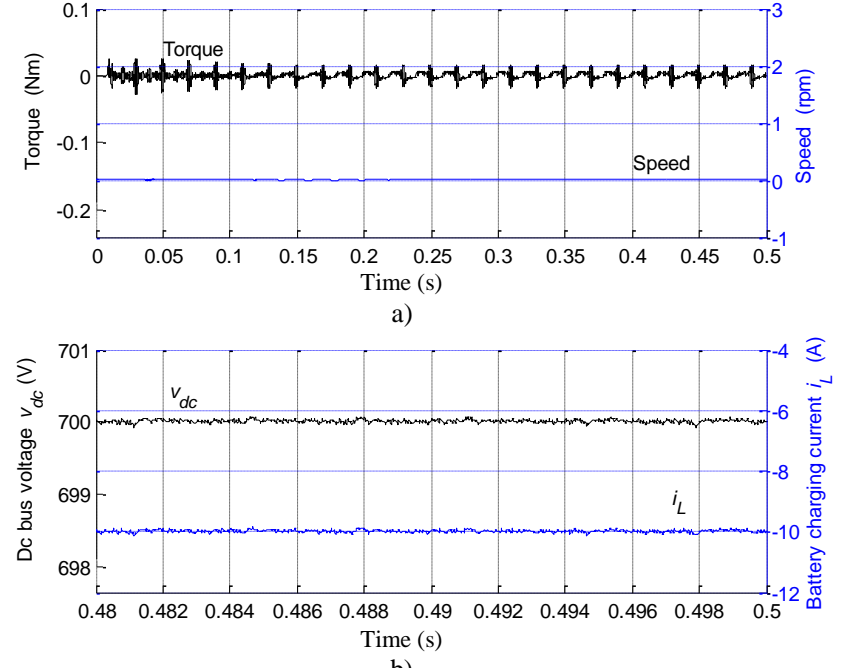

b)

Fig. 11. (a) First machine's torque and speed, (b) dc-bus voltage and charging current.

torque production in this mode of operation. The machine's speed is kept at zero during the whole V2G process. Fig. $11 \mathrm{~b}$ demonstrates that the dc-bus voltage is controlled to the reference value. The battery current has the same absolute value as for the charging mode; however it now has the opposite sign.

\section{CONCLUSION}

The paper proposes a new fast on-board charger applicable to four-motor EVs. The charger is completely integrated and does not require any additional components except those that are needed for the propulsion, and therefore already exist on board. Moreover, it does not require any hardware reconfiguration between the charging and propulsion modes of operation. It operates at unity power factor and can achieve both the charging and V2G mode. The additional advantage of the proposed charger is that it can employ the interleaving process in order to highly supress the current ripple that is taken/injected into the grid. Good performances of the charger and torque-free operation are confirmed by simulations for both charging and V2G mode.

\section{REFERENCES}

[1] M. Yilmaz, and P.T. Krein, "Review of battery charger topologies, charging power levels and infrastructure for plug-in electric and hybrid vehicles", IEEE Transactions on Power Electronics, vol. 28, no. 5 , pp. $2151-2169,2013$.

[2] J.M. Slicker, "Pulse width modulation inverter with battery charger", US Patent 4,491,768, 1985.

[3] M. Bertuoluzzo, N. Zabihi, and G. Buja, "Overview on battery chargers for plug-in electric vehicles", Int. Power Electronics and Motion Control Conf. EPE-PEMC, Novi Sad, Serbia, CD-ROM, 2012.

[4] W. E. Rippel, "Integrated traction inverter and battery charger apparatus", US patent No. 4,920,475, 1990.

[5] W. E. Rippel and A. G. Cocconi, "Integrated motor drive and recharge system", US patent No. 5,099,186, 1992.

[6] A. G. Cocconi, "Combined motor drive and battery recharge system", US Patent No. 5,341,075, 1994.

[7] J. de Santiago, H. Bernhoff, B. Ekergård, S. Eriksson, S. Ferhatovic, R. Waters, and M. Leijon, "Electrical motor drivelines in commercial all-electric vehicles: A review," IEEE Trans. on Vehicular Technology, vol. 61, no. 2, pp. 475-484, 2012.
[8] S. Kinoshita, "Electric system of electric vehicle," US Patent No. $5,629,603,1997$

[9] F. Lacressonniere and B. Cassoret, "Converter used as a battery charger and a motor speed controller in an industrial truck," Proc. Eur. Conf. on Power Electr. and Applications EPE, Dresden, Germany, CD-ROM paper 0159, 2005.

[10] S. Haghbin, S. Lundmark, M. Alakula, and O. Carlson, "An isolated high-power integrated charger in electrified-vehicle applications," IEEE Trans. on Vehicular Technology, vol. 60, no. 9, pp. 4115-4126, 2011.

[11] L. De Sousa, B. Silvestre, and B. Bouchez, "A combined multiphase electric drive and fast battery charger for electric vehicles," Proc. IEEE Vehicle Power and Propulsion Conference VPPC, Lille, France, CD-ROM, 2010.

[12] I. Subotic, E. Levi, M. Jones, and D. Graovac, "On-board integrated battery chargers for electric vehicles using nine-phase machines," IEEE Int. Electric Machines and Drives Conf. IEMDC, Chicago, IL, pp. 239-246, 2013.

[13] Renault press kit, "Renault ZOE: the electric supermini for everyday use," www.media.renault.com, February 26, 2013.

[14] I. Subotic, E. Levi, M. Jones, and D. Graovac, “An integrated battery charger for EVs based on an asymmetrical six-phase machine," IEEE Industrial Electronics Society Conf. IECON, Vienna, Austria, pp. 7242-7247, 2013.

[15] I. Subotic, E. Levi, M. Jones, and D. Graovac, "Multiphase integrated on-board battery chargers for electrical vehicles," Proc. European Power Electronics and Applications Conf. EPE, Lille, France, CDROM paper 0304, 2013.

[16] E. Levi, M. Jones, S.N. Vukosavic, and H.A. Toliyat, "A novel concept of a multiphase, multimotor vector controlled drive system supplied from a single voltage source inverter," IEEE Trans. on Power Electronics, vol. 19, no. 2, pp. 320- 335, 2004.

[17] S. Seung-Ki, L. Sang-Joon, "An integral battery charger for fourwheel drive electric vehicle," IEEE Trans. on Industry Applications, vol. 31, no. 5, pp. 1096-1099, 1995.

[18] S. Dusmez, A. Cook, and A. Khaligh, "Comprehensive analysis of high quality power converters for level 3 off-board chargers," Proc. IEEE Vehicle Power and Propulsion Conf. VPPC, Chicago, Illinois, CD-ROM, 2011.

[19] G. Pellegrino, E. Armando, P. Guglielmi, "An integral battery charger with power factor correction for electric scooter," IEEE Transactions on Power Electronics, vol. 25, no. 3, pp. 751-759, 2010.

[20] G. Gui-Jia, T. Lixin, "Control of plug-in hybrid electric vehicles for mobile power generation and grid support applications, "Proc. IEEE Applied Power Electronics Conf. APEC, Palm Springs, California, pp. 1152-1157, 2010.

\section{BIOGRAPHIES}

Ivan Subotic received his MSc degree in Electrical Engineering from the University of Belgrade, Serbia in 2011. He is currently a PhD student at Liverpool John Moores University. His main research interests include power electronics and control of multiphase drive systems.

Martin Jones received his BEng degree (First Class Honours) in Electrical Engineering from the Liverpool John Moores University, UK in 2001. He has been a research student at the Liverpool John Moores University from September 2001 till spring 2005, when he received his $\mathrm{PhD}$ degree. Dr Jones was a recipient of the IEE Robinson Research Scholarship for his $\mathrm{PhD}$ studies and is currently with Liverpool John Moores University as a Reader. His research is in the area of high performance ac drives.

Emil Levi received his MSc and the $\mathrm{PhD}$ degrees from the University of Belgrade, Yugoslavia in 1986 and 1990, respectively. He joined Liverpool John Moores University, UK in May 1992 and is, since 2000, Professor of Electric Machines and Drives. He served as a Co-Editor-in-Chief of the IEEE Trans. on Industrial Electronics from 2009 until 2013, and is currently an Editor of the IEEE Trans. on Energy Conversion and Editorin-Chief of the IET Electric Power Applications. He is a Fellow of the IEEE and the recipient of the Cyril Veinott "Electromechanical Energy Conversion Award" of the IEEE Power and Energy Society for 2009 and the Best Paper Award of the IEEE Trans. on Industrial Electronics for 2008 . 